\title{
POLÍTICA FISCAL MINERA EN UN CONTEXTO DE GANANCIAS EXTRAORDINARIAS: EL CASO DEL PERÚ 2000-2016*
}

\author{
Recibido: 20 de febrero de 2018 - Aprobado: 31 de agosto de 2018 \\ https://doi.org/10.22395/seec.v21n48a3
}

\section{Víctor Torres Cuzcano**}

\section{RESUMEN}

El artículo tiene como principal objetivo analizar la precisión de los instrumentos fiscales implementados en la política fiscal minera del Perú durante el singular incremento del precio de los metales del período 2003-2012. Para tal efecto, se evalúa la política fiscal minera de los gobiernos que se sucedieron durante dicha década de bonanza. Se concluye que los instrumentos de política fiscal que se aplicaron no fueron los más eficaces para asegurar una óptima apropiación de la renta minera por parte del Estado. Ello conduce a proponer dos instrumentos alternativos: las regalías ad valorem y el impuesto sobre las rentas de recursos naturales.

\section{PALABRAS CLAVE}

Impuestos; países menos desarrollados; recursos y desarrollo; conflictos mineros; Perú.

\section{CLASIFICACIÓN JEL}

$\mathrm{H} 21, \mathrm{Q} 32, \mathrm{Q} 34$

\section{CONTENIDO}

Introducción; 1. El marco teórico; 2. Las ganancias extraordinarias en la minería peruana; 3. La política fiscal frente a las ganancias extraordinarias; 4. Precisión de los instrumentos fiscales y recaudación óptima de la renta minera; 5. Instrumentos fiscales alternativos; 6. Conclusiones y recomendaciones; Bibliografía.

- El artículo resume los temas principales desarrollados por el autor en la tesis para obtener el título en el Máster Universitario Oficial en Hacienda Pública y Administración Financiera y Tributaria 2016-2017, Universidad Nacional de Educación a Distancia (UNED), España.

* Economista, Universidad Nacional Mayor de San Marcos, Lima, Perú. Magíster y doctor en SocioEconomía del Desarrollo, Universidad París 1 Panthéon-Sorbonne, París, Francia. Máster en Hacienda Pública y en Administración Financiera y Tributaria, UNED, Madrid, España. Profesor asociado e investigador, Facultad de Ciencias Económicas, UNMSM, Lima, Perú. Dirección: Av. Universitaria/Calle Germán Amézaga 375, Ciudad Universitaria, Lima 1. Correo electrónico: vtorresc1@unmsm.edu.pe. 


\title{
MINING FISCAL POLICY IN A CONTEXT OF EXTRAORDINARY GAINS: THECASE OF PERU 2000-2016
}

\begin{abstract}
This paper's main objective is to analyze the accuracy of the fiscal instruments implemented in Peru's mining fiscal policy during the particular increase in the metals' prices from 2003 to 2012 For this purpose, the mining fiscal policies of the successive governments during such decade of prosperity were evaluated. It is concluded that the fiscal policy instruments applied were not the most effective to ensure an optimal appropriation by the State of the mining income. This leads to the proposal of two alternative instruments: ad valorem royalties and income tax on natural resources.
\end{abstract}

\section{KEYWORDS}

Taxes; underdeveloped countries; developing countries; resources and development; mining conflicts; Peru.

\section{JEL CLASSIFICATION}

$\mathrm{H} 21, \mathrm{Q} 32, \mathrm{Q} 34$

\section{CONTENT}

Introduction; 1. Theoretical framework; 2. Extraordinary profits in Peruvian mining; 3. Fiscal policy against extraordinary profits; 4 . Fiscal instrument accuracy and optimal collection of mining income; 5 . Alternative fiscal instruments; 6. Conclusions and recommendations; Bibliography.

\section{POLÍTICA FISCAL DO SETOR MINERAL NUM CONTEXTO DE LUCROS EXTRAORDINÁRIOS: 0 CASO DO PERU 2000-2016}

\section{RESUMO}

Este artigo tem como principal objetivo analisar a exatidão dos instrumentos fiscais implantados na política fiscal do setor mineral do Peru, durante o singular aumento do preço dos metais entre 2003 e 2012. Para isso, avalia-se a política fiscal do setor mineral dos governos durante essa década de prosperidade. Conclui-se que os instrumentos de política fiscal que foram aplicados não foram os mais eficazes para garantir uma ótima apropriação da renda mineradora por parte do Estado. Isso nos conduz a propor dois instrumentos alternativos: as regalias ad valorem e o imposto sobre as rendas de recursos naturais.

\section{PALAVRAS-CHAVE}

Impostos; países menos desenvolvidos; recursos e desenvolvimento; conflitos mineradores; Peru.

\section{CLASSIFICAÇÃO JEL} H21, Q32, Q34

\section{CONTEÚDO}

Introdução; 1. Referencial teórico; 2. Lucros extraordinários na mineração peruana; 3. Política fiscal ante os lucros extraordinários; 4. Exatidão dos instrumentos fiscais e arrecadação da renda mineradora; 5. Instrumentos fiscais alternativos; 6 . Conclusões e recomendações; Bibliografia. 


\section{INTRODUCCIÓN}

En América Latina, el ciclo expansivo del precio de los commodities inaugurado en los primeros años del presente siglo, impulsó procesos de crecimiento socio-económico que se sostuvieron, en buena medida, en los elevados ingresos fiscales vinculados a las ganancias extraordinarias obtenidas en la explotación de recursos naturales no renovables. Sin embargo, su agotamiento hacia 2012-2013 trajo consigo una desaceleración del Producto Interno Bruto (PIB) y la caída de la recaudación, lo que recuerda una lección que no se ha terminado de aprender: la política fiscal se vuelve vulnerable e inestable cuando se sustenta, principalmente, en ingresos que se originan en la exportación de materias primas.

En el caso del alza del precio de los metales, tan importante como dicha constatación lo es el preguntarse si durante la década del boom minero (2003-2012) se recaudó todo lo que debía recaudarse. El Perú constituye un buen estudio de caso para responder a esta interrogante, a saber, si la política fiscal minera fue la más adecuada para la apropiación óptima de la renta minera durante dicho período, tema que se constituye en el principal objetivo de este artículo. Según Torres (2018, p.3), "en los años de mayor efervescencia del boom minero, la minería metálica aportó más del $60 \%$ de las exportaciones [totales del país] y contribuyó con poco más del 50 \% del impuesto" que grava las utilidades empresariales.

En los últimos diez años, en el Perú se han venido publicando investigaciones que han tenido como principal preocupación el análisis del referido boom minero: Cooperacción (2009, 2007), Torres (2013), Mendoza y De Echave (2016), entre otras publicaciones. Estos trabajos se han concentrado principalmente en la magnitud de las ganancias extraordinarias y en la distribución de la renta generada (canon y regalías principalmente) entre los distintos niveles de gobierno y las poblaciones vecinas a la explotación minera. Sin embargo, no se ha insistido lo suficiente en la idoneidad de las políticas fiscales que se implementaron para una óptima apropiación de la renta minera por parte del Estado. En esta línea de reflexión, en la presente investigación, se analiza la eficacia de la política fiscal minera que se aplicó en el Perú durante la década 2003-2012, cuando el sector minero obtuvo ganancias extraordinarias debido al alza sostenida del precio de los metales. Se evalúa la precisión de los instrumentos fiscales implementados por los tres gobiernos que se sucedieron en el Perú durante dicho período, lo cual sirve de sustento para proponer la aplicación de dos instrumentos fiscales alternativos: la regalía minera ad valorem y el impuesto sobre las rentas de recursos naturales.

El artículo se organiza en seis secciones, además de la introducción. La primera analiza el marco teórico de la política fiscal vinculada a los recursos naturales no 
renovables; la segunda estima la magnitud de los ingresos extraordinarios que obtuvo la minería peruana; la tercera analiza los instrumentos de política fiscal implementados para la captación óptima de la renta minera; la cuarta evalúa la precisión de dichos instrumentos; la quinta, propone el uso de instrumentos fiscales alternativos; en la sexta sección se exponen las principales conclusiones de la investigación.

\section{MARCO TEÓRICO}

El renovado interés en el estudio de la política fiscal y su relación con la renta generada en los sectores que explotan recursos naturales no renovables se justifica por dos hechos principales. Por un lado, en no pocos países, particularmente en América Latina, los ingresos fiscales derivados de los recursos naturales juegan un rol importante en su desenvolvimiento socioeconómico. Por otro lado, el precio internacional de las materias primas alcanzó niveles sin precedentes durante la década 2003-2012, lo que se tradujo en la obtención de ganancias extraordinarias en dichos sectores (metales e hidrocarburos en particular), y en un singular aumento de los ingresos fiscales.

En este contexto, resulta pertinente preguntarse si los ingresos fiscales recaudados por las administraciones tributarias (AATT) de la región durante dicho período alcanzaron un nivel óptimo, y si ello no fue así, qué motivó este resultado. La búsqueda de una respuesta a este interrogante nos conduce al análisis de un tema que, durante el presente siglo, ha renovado la atención de la literatura especializada en el estudio del binomio política fiscal-recursos naturales no renovables'. Nos referimos a cómo lograr una óptima participación del Estado en la renta ${ }^{2}$ proveniente de estas industrias extractivas ${ }^{3}$ (government take), sin desalentar la inversión privada. En esta línea de reflexión pueden mencionarse, entre otros, los siguientes trabajos: Banco Interamericano de Desarrollo (BID, 2013), Boadway y Keen (2014), Garnaut (2010), Gómez, Jiménez y Morán (2015), Guj (2012), Guj et al. (2013), Land (2008).

\subsection{Instrumentos fiscales para capturar la renta de las industrias extractivas}

Los ingresos fiscales vinculados a los recursos naturales no renovables se recaudan a partir de instrumentos que pueden ser clasificados en tributarios y no tributarios. Según el BID (2013, p.274), entre los primeros están los impuestos que gravan las

La función que cumplen las AATT -claro está- coadyuva de manera importante a responder el interrogante arriba planteado, sin embargo, no es el objetivo de la presente investigación profundizar en este tema.

2 En concordancia con el FMI (2012, p. 9), por renta se entiende "el excedente de los ingresos menos los costos de producción, incluidos los costos de exploración y desarrollo, así como la tasa de retorno normal del capital".

3 Minería, petróleo y gas. 
utilidades obtenidas por las empresas (en adelante, impuesto sobre sociedades), "las retenciones, los impuestos progresivos sobre las ganancias, los impuestos sobre los beneficios inesperados o extraordinarios y los impuestos a las exportaciones". Entre los no tributarios se cuentan: las regalías (royalties), "las tarifas y los pagos por derechos de prospección, los contratos de producción compartida y servicios, y los ingresos por la participación del Estado en la propiedad" de los recursos extraídos (incluye "los dividendos y transferencias de las empresas de petróleo nacionales"). Sin embargo, esta amigable clasificación esconde un bosque enmarañado de esquemas impositivos. En efecto, los instrumentos fiscales aplicados a la industria de recursos naturales no renovables han ganado en diversificación y complejidad durante las últimas décadas. Según Gómez, Jiménez, y Morán (2015, p.15), "impuestos con idéntica denominación poseen distintas variantes según el país estudiado".

En Garnaut (2010) se identifican seis formas principales de gravar a la industria extractiva, las cuales pueden combinarse en varios híbridos:

- Tarifa plana.

- Regalías específicas o ad valorem.

- La tasa más alta de un impuesto proporcional sobre los beneficios.

- Impuesto progresivo sobre los beneficios.

- Impuesto sobre las rentas de recursos naturales.

- Brown Tax 4.

En cuanto a las bondades o eficacia de estos instrumentos, el International Council on Mining and Metals (ICMM) (2009) considera que la imposición fiscal en las industrias extractivas debe basarse en la renta o beneficios que obtiene la empresa, no en la producción o ventas. Para el Fondo Monetario Internacional (FMI) (2012, p.6), "un régimen que combine una regalía y un impuesto que grave de manera expresa las rentas vinculadas a recursos naturales (junto con el impuesto sobre sociedades) atrae a muchos países en desarrollo". Como bien nos recuerdan Boadway y Keen (2014), el intercambio de opiniones en torno a las ventajas y desventajas de estos dos grupos de instrumentos genera muchas veces discusiones acaloradas.

Según Garnaut (2010), el Brown Tax recibe este nombre por el trabajo del economista americano E. Cary Brown, publicado en 1948. Es el menos conocido de estas seis formas de imposición. Brown originalmente lo sugirió como un sustituto del impuesto sobre sociedades estándar, pero en la práctica ha sido aplicado como un impuesto especial sobre la renta minera. 


\subsubsection{La aplicación de regalías}

Las regalías son el pago que la empresa minera hace al Estado por el uso de un recurso natural de propiedad pública. Pueden adoptar diversas formas, pero su característica general es que se basan en la cantidad de recursos extraídos cada período, en términos de valor (regalías ad valorem), o de unidad producida (regalías específicas). No pocos autores, como por ejemplo Boadway y Keen (2014), BID (2013), Gómez, Jiménez, y Morán (2015), consideran que las regalías son ineficaces o que afectarían en gran medida las decisiones de inversión de las empresas mineras. Según el BID (2013), las regalías afectarían las decisiones de inversión de dos maneras principalmente. Por un lado, si se fijan por unidad producida, se invertirá solo en los proyectos o minas con alta rentabilidad y se abandonará aquellas cuya operación implique un mayor costo de producción. Además, en épocas de alza del precio de los metales, toda la ganancia queda en manos de los productores. Por otro lado, cuando la regalía se impone sobre el valor de las ventas, mejora la apropiación de la renta minera por parte del Estado en períodos de cotizaciones al alza, pero perjudica la rentabilidad de la producción debido a las elevadas inversiones que esta requiere.

Un tercer tipo de regalías (profit-based royalty) aplica una tasa determinada sobre los beneficios o utilidades. Según Guj et al. (2013), este tipo de regalías es más eficiente económicamente en comparación con las regalías específicas y ad valorem, pero es más complejo de administrar tanto para las compañías como para el gobierno. Para Boadway y Keen (2014), las regalías imponen distorsiones en la producción de recursos, a menos que sean diseñadas de manera artificial para imitar un impuesto sobre la renta de flujo de caja. Al mismo tiempo, sin embargo, estos autores consideran que las regalías pueden justificarse debido a las asimetrías de información entre el gobierno y la empresa, perspectiva que también es compartida por el FMI (2012). Este tema lo retomamos más adelante.

\subsubsection{La imposición sobre las rentas}

Los impuestos que se imponen sobre la renta minera interferirían menos que las regalías en las decisiones de producción e inversión. Gómez, Jiménez, y Morán (2015) consideran que estos impuestos tienden a ser más neutrales, aunque no totalmente, pues la normativa nacional sobre la depreciación a ser aplicada sobre la inversión inicial y otros beneficios fiscales pueden influir en las decisiones de inversión. Los impuestos que gravan la renta de las industrias extractivas admiten una amplísima variedad (ver tabla 1), siendo el de más amplia aplicación el impuesto sobre sociedades. Para Gómez, Jiménez y Morán (2015, p.25), en la práctica, los países 
tienden a superponer ambos instrumentos -regalías e impuestos sobre las rentas-, aplicándolos sobre una misma base imponible, esto produce el efecto de incrementar el margen de apropiación estatal. La superposición se produciría "a partir del 'punto de equilibrio' de la actividad productiva, es decir, donde los ingresos totales - con las deducciones fiscales permitidas- llegan a cubrir los costos del proyecto". Además, por lo general, el pago de regalías es considerado como un crédito fiscal en la determinación del impuesto sobre sociedades, con lo cual el efecto negativo arriba mencionado prácticamente desaparecería.

\section{Tabla 1. Instrumentos fiscales en las industrias extractivas}

\begin{tabular}{|c|c|c|c|}
\hline & $\begin{array}{l}\text { Regalías sobre los } \\
\text { ingresos brutos }\end{array}$ & $\begin{array}{l}\text { Impuestos sobre las } \\
\text { rentas de los recursos } \\
\text { naturales }\end{array}$ & $\begin{array}{l}\text { Impuestos sobre las } \\
\text { sociedades e impues- } \\
\text { to variable sobre la } \\
\text { renta de las socieda- } \\
\text { des (IVR) }\end{array}$ \\
\hline $\begin{array}{l}\text { Maximizar el valor } \\
\text { presente neto (VPN) } \\
\text { para el Estado. }\end{array}$ & $\begin{array}{l}\text { Frena algunos pro- } \\
\text { yectos y no captura } \\
\text { el up-side de los o } \\
\text { proyectos que si- } \\
\text { guen adelante. }\end{array}$ & $\begin{array}{l}\text { Captura un mayor VPN } \\
\text { esperado para el go- } \\
\text { bierno a cambio de que } \\
\text { se asuma el riesgo. }\end{array}$ & $\begin{array}{l}\text { Relativamente neutro } \\
\text { y progresivo. Vulnera- } \\
\text { bilidad a la subcapita- } \\
\text { lización. }\end{array}$ \\
\hline $\begin{array}{l}\text { Progresividad cuando } \\
\text { el precio determina } \\
\text { rendimientos más } \\
\text { altos. }\end{array}$ & $\begin{array}{l}\text { No responde: regre- } \\
\text { sivo. }\end{array}$ & $\begin{array}{l}\text { Captura el beneficio } \\
\text { cualquiera que sea la } \\
\text { causa. Automáticamen- } \\
\text { te reduce la carga en } \\
\text { proyectos de alto costo. }\end{array}$ & $\begin{array}{l}\text { Respuesta instantá- } \\
\text { nea del IVR a las varia- } \\
\text { ciones de los costos. }\end{array}$ \\
\hline $\begin{array}{l}\text { Neutralidad, evitar } \\
\text { que se distorsionen } \\
\text { las decisiones de in- } \\
\text { versión y operativas (y } \\
\text { de ese modo disipar el } \\
\text { potencial de ingresos). }\end{array}$ & $\begin{array}{l}\text { Riesgo de frenar } \\
\text { proyectos margina- } \\
\text { les y acortar el ciclo } \\
\text { de vida/reducen la } \\
\text { producción de pro- } \\
\text { yectos viables. }\end{array}$ & $\begin{array}{l}\text { Neutro: la participación } \\
\text { solo la pagan proyectos } \\
\text { que realmente superan } \\
\text { el rendimiento mínimo. }\end{array}$ & $\begin{array}{l}\text { Depende del diseño } \\
\text { de los parámetros. } \\
\text { Potencial distorsión } \\
\text { en el IVR por la de- } \\
\text { preciación (cambio } \\
\text { drástico de la tasa). }\end{array}$ \\
\hline $\begin{array}{l}\text { Garantizar incentivos } \\
\text { adecuados para la } \\
\text { inversión. }\end{array}$ & $\begin{array}{l}\text { Disuasiva si es de- } \\
\text { masiado alta. Au- } \\
\text { menta el riesgo de } \\
\text { proyectos inviables. }\end{array}$ & $\begin{array}{l}\text { Efecto disuasivo mo- } \\
\text { derado en tanto haya } \\
\text { un beneficio suficiente } \\
\text { para el inversionista. }\end{array}$ & $\begin{array}{l}\text { Eficaz en tanto la tasa } \\
\text { máxima no se fije a un } \\
\text { nivel demasiado alto. }\end{array}$ \\
\hline $\begin{array}{l}\text { Riesgo para el gobier- } \\
\text { no. }\end{array}$ & $\begin{array}{l}\text { Riesgo a cargo del } \\
\text { inversionista. }\end{array}$ & $\begin{array}{l}\text { Riesgo a cargo del go- } \\
\text { bierno: de no recibir } \\
\text { ingresos, o hacerlo sólo } \\
\text { en etapas tardías. }\end{array}$ & $\begin{array}{l}\text { El gobierno asume el } \\
\text { riesgo si la tasa míni- } \\
\text { ma del IVR es inferior } \\
\text { a la tasa del impuesto } \\
\text { sobre las sociedades. }\end{array}$ \\
\hline
\end{tabular}

Fuente: FMI $(2012$, p.16). 


\subsubsection{El impuesto sobre las rentas puras}

El debate teórico en torno al binomio política fiscal-recursos naturales no renovables, ha girado en torno a cuál sería el instrumento ideal de tributación, aquel que, además de transferir al Estado el máximo nivel de ingresos fiscales, permita que el productor obtenga un rendimiento normal en sus inversiones. La literatura especializada identifica como lo más cercano a ese ideal al denominado impuesto sobre la renta económica pura. Retomando a Land (2008), en Gómez, Jiménez y Morán (2015, p.19) se define la renta económica pura de un recurso natural no renovable como el excedente del valor bruto de producción que se obtiene después de restar todos los costos inherentes a la explotación de un depósito, "incluyendo las remuneraciones de todos los factores de producción. Estas últimas incluyen una retribución mínima como compensación del capital invertido, la cual equivale a la tasa de interés de largo plazo más un margen adicional para compensar los riesgos técnicos, comerciales y políticos asociados a la inversión".

En el trabajo del FMI (2012), se identifican dos grupos principales de impuestos sobre las rentas puras de las industrias extractivas, aunque -en la práctica $\square$ el número de esquemas impositivos es mayor.

Por una parte, el Brown Tax o impuesto sobre el flujo de caja base R. En su versión pura, el Brown Tax grava el flujo de efectivo positivo que resulta de la diferencia entre los ingresos y gastos corrientes de una compañía minera. Cuando el flujo de caja es negativo, el Gobierno proporciona un reembolso inmediato. Como bien se precisa en The Senate (2012b, p.6), este modelo de imposición "es difícil de implementar debido a la naturaleza inmediata del reembolso". Una variante que busca replicar los efectos del Brown Tax es el impuesto sobre las rentas de recursos naturales (RRT, por sus siglas en inglés: Resource Rent Tax). En el esquema propuesto por los economistas australianos Ross Garnaut y Anthony Clunies Ross en 1975, el RRT no reembolsa los flujos de efectivo negativos o las pérdidas en que incurre el contribuyente. En su lugar, según The Senate (2012b, p.6), "las pérdidas son arrastradas y 'elevadas' [uplifted] por una tasa de interés, de modo que se puedan usar como una deducción contra los flujos de efectivo positivos en años posteriores". Esta tasa uplift es la tasa de retorno mínima requerida por el inversionista. Toda vez que los gastos de capital se deducen conforme se van efectuando, no se incluye la depreciación contable en el cálculo de los gastos. Tampoco se consideran los intereses u otros costos financieros.

Australia aplicó este instrumento fiscal a la producción de mineral de hierro y carbón desde el 1 de julio de 2012 (impuesto sobre la renta de recursos minerales -MRRT , por sus siglas en inglés), pero lo derogó el 30 de septiembre de 2014. No obstante, sigue aplicando un impuesto sobre la renta de recursos petroleros (PRRT, por sus siglas en inglés). Según el FMI (2012, p.20), "Angola lo aplica en contratos 
de producción compartida"; en tanto que Guj et al. (2013) afirman que hubo intentos fallidos de aplicar el RRT en la producción de minerales de Papúa Nueva Guinea y una provincia de Canadá. Por lo general, el RRT se aplica bajo el criterio del perímetro fiscal (ring-fencing ${ }^{5}$ ); es decir, la empresa minera no puede compensar sus cargas tributarias entre sus diferentes proyectos de explotación. Sin embargo, ello no siempre ocurre así 6 . Dentro de este grupo de impuestos se encuentra también el denominado Factor-R, utilizado en la industria del petróleo, así llamado debido a que el impuesto se aplica cuando se supera un "ratio", umbral o tasa de retorno mínimo de la inversión.

Por otra parte, están los esquemas de deducción sobre el patrimonio o el capital de la empresa. En este segundo grupo de impuestos se distingue entre la deducción del patrimonio neto de la empresa (ACE, por sus siglas en inglés: Allowance for Corporate Equity) y la deducción del capital total de la empresa (ACC, por sus siglas en inglés: Allowance for Corporate Capital). Para el FMI (2012, p.20), el ACE modifica el impuesto sobre sociedades estándar al otorgar "una deducción por un rendimiento imputado sobre el patrimonio neto contable; se mantiene la depreciación contable, pero se vuelve irrelevante por cuanto una depreciación más rápida reduce el patrimonio y por ende las deducciones futuras por idéntico monto".

En el caso del ACC, se permite deducir los intereses a una tasa teórica, con lo cual se elimina toda distinción entre financiamiento mediante deuda o mediante capital propio. El momento en el que se debe efectuar el pago constituye una diferencia principal entre estos dos grupos de impuestos sobre las rentas. En el caso del Brown Tax, el impuesto se paga solo en la fecha en la que los costos hayan sido completamente recuperados; en el caso del ACE/ACC, el impuesto se paga si el ingreso anual cubre el costo anual del capital financiero. El cálculo de la tasa de retorno de cada proyecto constituye -según el FMI (2012, p.24) - "un tema fundamental y polémico para ambos grupos de impuestos: para el traslado a ejercicios futuros en el Brown Tax, para los costos de capital en el esquema ACE/ACC".

La adecuada estimación de la tasa de retorno se relaciona con un aspecto que en la presente investigación se considera de particular importancia: la minería que explota recursos naturales no renovables (o agotables) es una actividad económica

\footnotetext{
5 Según Chen y Perry (2015), el concepto de ring-fencing se entiende como una limitación en la consolidación de los ingresos y deducciones a efectos fiscales en los diferentes proyectos emprendidos por el mismo contribuyente.

6 Según The Senate (2012b), de los tres casos del MRRT que se implementaron en Australia, en uno de ellos el minero con dos o más proyectos que producen el mismo recurso imponible puede transferir las pérdidas no utilizadas de un proyecto a otro, siempre que el otro proyecto tenga suficientes beneficios mineros para absorber las pérdidas restantes una vez que haya aplicado sus propias regalías, pérdidas mineras y otras deducciones.
} 
donde el fallo de mercado conocido como información asimétrica es una posibilidad siempre presente: el productor minero es el único que cuenta con buena información sobre la estructura y magnitud de los gastos y costos involucrados en su proceso de producción, así como sobre los aspectos técnicos y comerciales de su proyecto productivo. Ello le deja margen para una manipulación de los costos que busque disminuir de manera artificial la tasa de retorno en cada uno de sus proyectos. Desde la perspectiva de Boadway y Keen (2014), la información asimétrica es particularmente acentuada en el sector de los recursos naturales no renovables, donde muchas empresas están integradas verticalmente y son multinacionales. Estas tendrían amplias oportunidades para evadir impuestos mediante los precios de transferencia y la asignación de costos para maximizar el valor de las deducciones fiscales.

\section{LAS GANANCIAS EXTRAORDINARIAS EN LA MINERÍA PERUANA}

Según Torres (2013, p.47), "en sus lineamientos básicos, los gobernantes que tuvo el Perú durante la primera década del siglo XXI7, Alejandro Toledo Manrique (julio 2001-julio 2006) y Alan García Pérez (julio 2006-julio 2011), continuaron con el modelo económico neoliberal que Alberto Fujimori impuso en julio de 1990". El Gobierno de Ollanta Humala (julio 2011-julio 2016), si bien intentó apartarse de este camino en los primeros años de su gestión, finalmente terminó alineándose con el statu quo predominante. Sin embargo, sostiene Torres (2014, p.180) que "dos aspectos estrechamente interrelacionados marcan un cambio sustancial con respecto al escenario socioeconómico que predominó en el sector minero nacional durante" la segunda mitad del siglo XX. Por un lado, un acentuado y sostenido incremento del precio internacional de los metales desde 2003, lo cual permitió la obtención de ganancias extraordinarias hasta mediados de la segunda década del presente siglo. Por otro, "un exacerbado desarrollo de conflictos socio-ambientales, que tuvieron como principales leitmotiv reivindicaciones ambientales" y una mayor participación en la renta minera. Ambos aspectos motivaron la intervención directa del Estado, vía la política fiscal, con el objetivo de alcanzar una mejor regulación en la distribución de las ganancias extraordinarias.

\subsection{Una estimación de los ingresos extraordinarios}

En la presente investigación, se han estimado los ingresos extraordinarios de las mineras a partir de sus ingresos por exportaciones. Para tal efecto, se retoma la metodología propuesta en Cooperacción (2007), según la cual, a fin de anular el alza inusual de los precios mineros registrada desde 2003, se utiliza un precio de exportación de largo plazo, el cual se calcula como el promedio simple del precio

$7 \quad$ El Perú tuvo un Presidente transitorio provisional, Valentín Paniagua Corazao, desde el 20 de noviembre de 2000 hasta el 28 de julio de 2001. 
anual de exportación de los minerales peruanos ${ }^{8}$ registrado durante los años previos a la década de bonanza. A diferencia de este procedimiento, para no sobrevalorar la estimación, se ha tomado en cuenta el promedio anual de los diez precios de exportación más altos durante los 23 años (1980-2002) que precedieron al boom minero. Los ingresos extraordinarios resultan de restar el valor de las exportaciones efectuadas a precios corrientes, menos el valor de las exportaciones efectuadas a precios congelados o de largo plazo.

Los resultados de este ejercicio muestran que los ingresos extraordinarios obtenidos durante 2003-2012 ascendieron a US\$ 80.867 millones. El 81,7 \% de dicho total se obtuvo durante el segundo quinquenio de la bonanza (US\$ 66.040 millones), lo cual se explica porque durante dicho período (2008-2012), el precio de los metales registró los mayores incrementos. Desde 2012, la cotización de los minerales comenzó a caer, pero se mantuvo por encima de los niveles registrados antes del boom minero. Ello explica el que los ingresos extraordinarios de las mineras durante los últimos cuatro años del análisis (US\$11.676 millones, en promedio anual), si bien se redujeron en cerca de $12 \%$ con respecto al quinquenio precedente (US\$13.208 millones), aún se mantenían muy por encima de los ingresos extraordinarios acumulados en los cinco primeros años de la bonanza minera (ver gráfica 1).

Gráfica 1. Minería: estimación de los ingresos extraordinarios debido al incremento del precio de los minerales 2003-2016 (millones US\$ - promedio anual)

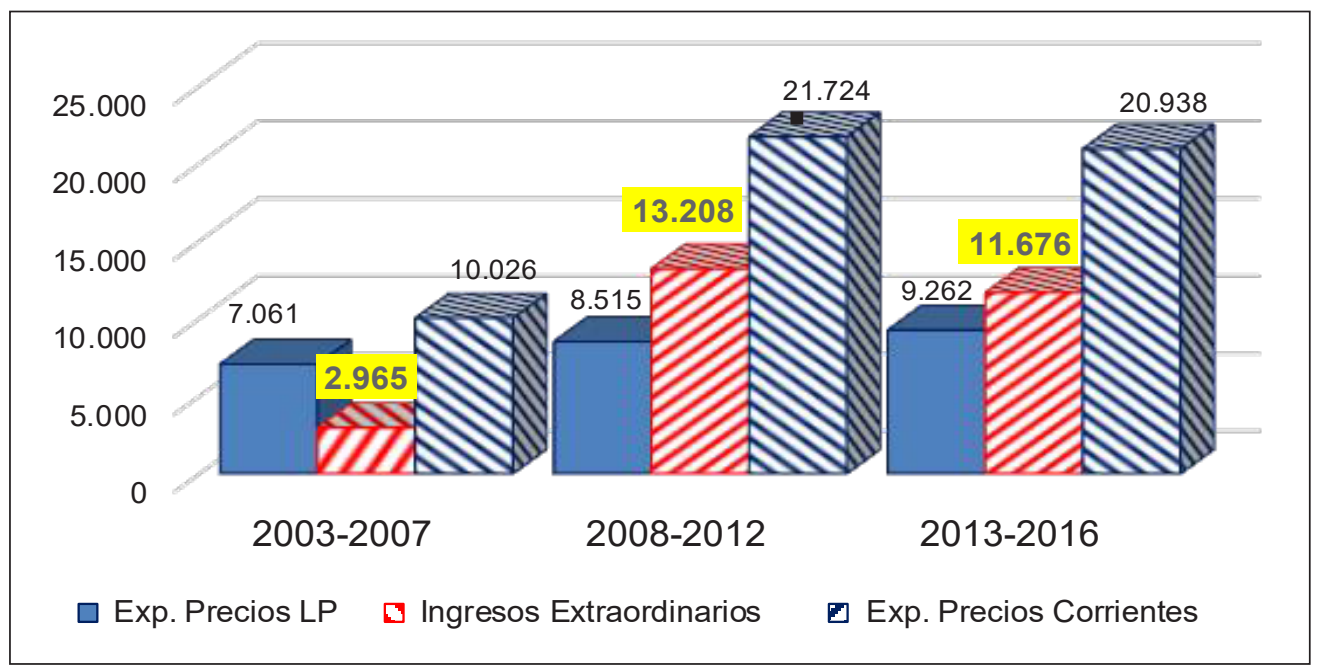

Fuente: BCRP, Ministerio de Energía y Minas (MINEM).

\footnotetext{
Se utiliza los precios de exportación que publica el Banco Central de Reserva del Perú (BCRP).
} 


\section{LA POLÍTICA FISCAL FRENTE A LAS GANANCIAS EXTRAORDINARIAS}

Durante el boom minero (2003-2012), el Estado buscó conciliar sus propios intereses (mayor recaudación) con los intereses divergentes de empresas y poblaciones mineras, mediante la implementación de instrumentos fiscales que le permitiesen capturar la creciente renta minera. Sin embargo, no todos los gobiernos que se beneficiaron del alza del precio de los metales tuvieron la misma predisposición para lograr dicho objetivo.

\subsection{El gobierno de Alejandro Toledo (julio 2001-julio 2006)}

Durante el gobierno del presidente Toledo se tomaron dos decisiones de particular importancia relacionadas con la apropiación de la renta minera por parte del Estado. La primera decisión fue implementar el alza del porcentaje del canon minero: del 20 \% que estuvo vigente entre enero de 1997 y mayo de 2002, a 50 \% a partir de junio de $2002^{9}$. El canon minero es definido como la participación de los gobiernos locales (municipalidades provinciales y distritales, en adelante GL) y gobiernos regionales (en adelante, GR) en el total de ingresos y rentas obtenidos por el Estado por la explotación económica de los recursos mineros (metálicos y no metálicos). Sin embargo, sostiene Torres (2013, p.61), un porcentaje más alto del "canon minero no significaba un esfuerzo adicional de parte de [las empresas mineras por] compartir sus ganancias extraordinarias con las poblaciones vecinas a sus operaciones"; tampoco implicaba una mayor participación del Estado en la renta minera. Ello es así porque el canon no es un nuevo tributo: es el $50 \%$ del impuesto sobre sociedades ${ }^{10}$ que pagan los titulares de la actividad minera, impuesto que todas las empresas están obligadas a pagar al Estado al margen del sector económico en el que operan.

En junio de 2004, el gobierno de Toledo adoptó una decisión importante para lograr el objetivo de una adecuada apropiación de la renta minera: la aplicación de regalías, que debían pagarse, además del impuesto sobre sociedades. La base de referencia para el pago de la regalía minera, que en adelante vamos a llamar antigua regalía minera (antigua RM) para diferenciarla del tipo de regalía que sería implementado desde septiembre de 2011, es el valor bruto de las ventas de concentrados, por tanto, se trata de una regalía del tipo ad valorem. La tasa de la antigua RM tiene tres niveles: $1 \%, 2 \%$ y $3 \%$, que se aplican según los tramos de venta del concentrado o su equivalente. En consecuencia, la tasa media de regalías es inferior al tres por

\footnotetext{
9 La decisión de subir el porcentaje del canon minero a 50 \% se tomó el 10 de julio de 2001 durante el gobierno transitorio provisional de Valentín Paniagua (Ley N. ${ }^{\circ}$ 27506, Ley de Canon).

10 La tasa del impuesto sobre sociedades es de 30 \% sobre todos los beneficios. Si la compañía minera cuenta con un contrato de estabilidad tributaria, debe pagar dos puntos porcentuales adicionales.
} 
ciento (ver tabla 2). El monto efectivamente pagado por concepto de la antigua RM es considerado como costo para efectos del impuesto sobre sociedades. Al igual que el canon minero, las regalías se destinan a los GL y GR donde se ubican los proyectos mineros.

Tabla 2. Antigua regalía minera

\begin{tabular}{|c|l|c|}
\hline Rangos & $\begin{array}{c}\text { Valor del concentrado } \\
\text { (millones de US\$ anuales) }\end{array}$ & Regalía (\%) \\
\hline $1 .^{\circ}$ & Hasta 60 & $1 \%$ \\
\hline $2 .^{\circ}$ & De 60 hasta 120 & $2 \%$ \\
\hline $3 .^{\circ}$ & Más de 120 & $3 \%$ \\
\hline
\end{tabular}

Fuente: Congreso de la República del Perú (2004)

Sin embargo, como se explica más adelante, las empresas más importantes de la minería a gran escala no pagaron la antigua RM porque se ampararon en sus contratos de estabilidad tributaria (CET). Los CET están definidos en la Constitución Política del Perú como contratos-ley, sobre cuya base el Estado establece garantías y otorga seguridades contractuales a los inversionistas, las cuales no pueden ser modificadas legislativamente. Por lo tanto, este instrumento fiscal empleado por el Estado para capturar un mayor porcentaje de la renta minera y regular una distribución más equitativa de las ganancias extraordinarias, no produjo los resultados esperados.

\subsection{El gobierno de Alan García (julio 2006-julio 2011)}

Alan García Pérez asumió la Presidencia de la República en julio de 2006, y las decisiones de política económica que se adoptaron durante su gobierno \según Torres (2014, p.183) $]$ buscaron "incentivar la inversión privada a cualquier costo. En el plano social, sin embargo, esta decisión contribuyó a agudizar los conflictos socio-ambientales". En el ámbito de la política fiscal minera, la característica fue una completa inacción. En medio de la presión de los conflictos socio-ambientales, al comenzar el gobierno de García se acentuó en el país el debate en torno a lo idóneo de crear un impuesto a las ganancias extraordinarias del sector minero, el denominado Windfall Tax.

La implementación de tal instrumento fiscal -que se hubiese sumado al impuesto sobre sociedades y a la antigua RM-, implicaba, necesariamente, renegociar los CET firmados entre las mineras y el Estado peruano. El gobierno del presidente García descartó esta alternativa. El Windfall Tax fue desestimado a pesar de que 
una misión del Departamento de Asuntos Fiscales del FMI (FAD, por sus siglas en inglés: Fiscal Affairs Department), que visitó el país entre el 20 de septiembre y el 4 de octubre de 2006, es decir, a los pocos meses de inaugurado dicho gobierno, concluyó -según Daniel, Adedeji y Medas (2007, p.7) - que el régimen fiscal aplicado en ese momento en la minería peruana no era "suficientemente progresivo en su estructura". Es decir, la participación del gobierno en los beneficios de los proyectos mineros no aumentaba en la misma medida que lo hacía la rentabilidad intrínseca de dichos proyectos.

En diciembre de 2006, se optó por negociar un acuerdo con las empresas mineras, denominado Programa Minero de Solidaridad con el Pueblo (PMSP), para que estas aportaran una contribución voluntaria a la mejora de las condiciones de vida de las poblaciones ubicadas en las áreas de influencia de las actividades mineras. Según Torres (2013, p.62), el PMSP "contemplaba un aporte voluntario del 3,75 \% de las utilidades netas (después de impuestos) de las empresas mineras, por un periodo de cinco años, siempre que los precios de los metales estuvieran por encima de un determinado umbral". La renovación automática anual del acuerdo también estaba condicionada a que el gobierno no cambiase el régimen tributario aplicable al sector. El programa estimó un aporte de US\$783 millones, aproximadamente, a ser invertidos durante el período 2007-2011. Con esta decisión, el gobierno de García mató dos pájaros de un solo tiro: por un lado, mantuvo las buenas relaciones con las mineras, sin reclamarles por el no pago de las regalías ni imponerles el Windfall Tax; por otro, en algo atendió las demandas de las poblaciones vecinas a la actividad minera, que exigían una mayor participación en las ganancias extraordinarias del sector. Por el lado de las empresas, el aporte voluntario no les significaba un esfuerzo adicional, pues estas ya venían diseñando e implementando gastos sociales y comunitarios en las áreas mineras para mitigar los conflictos socio-ambientales.

La política fiscal minera complaciente del gobierno de García privó al Estado peruano de ingresos fiscales a los que tenía justo derecho, a saber, la antigua RM y el Windfall Tax, precisamente en el quinquenio en el que el precio de los metales y los ingresos extraordinarios de las mineras alcanzaban sus máximos niveles. Del total de los ingresos extraordinarios que hemos estimado para el período 2003-2012, el gobierno de García concentró el 62,9 \%; Humala, el 33,7 \% y Toledo el 3,4 \% (ver gráfica 2).

\subsection{El gobierno de Ollanta Humala (julio 2011-julio 2016)}

La bonanza minera que comenzó en 2003, se interrumpió con la crisis financiera mundial de 2008, pero fue retomada desde 2010 y continuó durante dos años más. 
Sin embargo, según Torres (2015), ya no se obtuvieron, en términos relativos, las elevadas ganancias extraordinarias que caracterizaron a la etapa precrisis. Desde 2013, la política fiscal quedó supeditada a la urgencia de administrar el fin del boom minero y sus secuelas en términos de acentuada contracción de los ingresos fiscales y desaceleración de la actividad económica. Este es el escenario que le tocó vivir al gobierno del Presidente Humala, el que a pesar de ello -o más bien, debido a ello- representó un cambio importante con respecto a la inacción que caracterizó a la política fiscal minera desde junio de 2004, cuando se creó la antigua RM. El 28 de septiembre de 2011, se introdujeron tres cambios sustanciales en los instrumentos fiscales -tributarios y no tributarios- que gravaban al sector minero (ver tabla 3). El objetivo era incrementar los ingresos fiscales, pero también alcanzar una mayor participación del gobierno central en la distribución de la renta minera, aunque al costo de reducir la participación de los GL y GR. Por un lado, se introdujo modificaciones importantes en la antigua RM, dando lugar a lo que en esta investigación llamamos nueva regalía minera (en adelante, nueva RM). Se trata, en estricto sentido, de un nuevo instrumento fiscal, pues mientras la antigua RM se aplica sobre el valor de venta del mineral, la nueva RM grava la utilidad operativa ${ }^{11}$; es decir, es del tipo profit-based royalty. La antigua RM ha seguido siendo pagada por un número cada vez menor de empresas que la estabilizaron en sus CET.

Gráfica 2. Sector minero: estimación de los ingresos extraordinarios según gobiernos 2003-2012 (millones US\$)

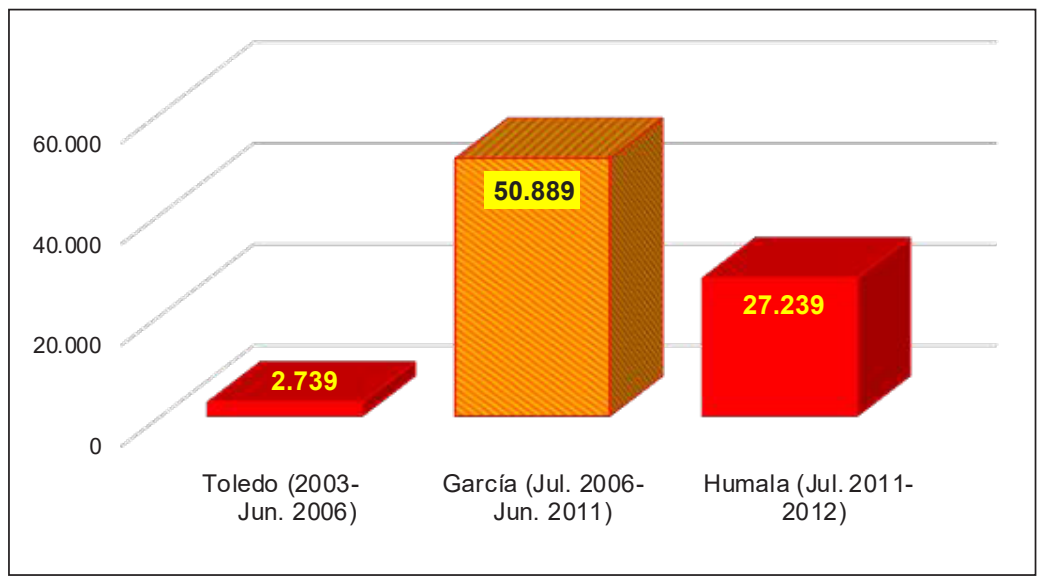

Fuente: Banco de la República del Perú-Ministerio de Minas y Energía del Perú 11 La utilidad operativa se obtiene después de restar a los ingresos por ventas, el costo de ventas y los
gastos operativos, además de las depreciaciones, amortizaciones y gastos de exploración. 
Tabla 3. Sector minero: instrumentos fiscales implementados desde septiembre 2011

\begin{tabular}{|c|c|c|c|c|}
\hline $\begin{array}{l}\text { Obligación } \\
\text { fiscal }\end{array}$ & Base legal & Contribuyentes & Base imponible & Tasa \\
\hline $\begin{array}{l}\text { Nueva } \\
\text { regalía } \\
\text { minera } \\
\text { (nueva } \\
\text { RM). }\end{array}$ & $\begin{array}{l}\text { Ley } N^{\circ} .29788, \\
\text { publicada el } 28 \\
\text { de septiembre de } \\
2011 .\end{array}$ & $\begin{array}{l}\text { Sujetos de la activi- } \\
\text { dad minera que no } \\
\text { contaban con CET y } \\
\text { estaban pagando la } \\
\text { antigua RM. }\end{array}$ & $\begin{array}{l}\text { Utilidad ope- } \\
\text { rativa trimes- } \\
\text { tral. }\end{array}$ & $\begin{array}{l}\text { Tasas marginales pro- } \\
\text { gresivas en un rango } \\
\text { de } 1,00 \% \text { a } 12,00 \% \text {, en } \\
\text { función de } 16 \text { tramos } \\
\text { crecientes del margen } \\
\text { operativo de la empre- } \\
\text { sas. }\end{array}$ \\
\hline $\begin{array}{l}\text { Impues- } \\
\text { to espe- } \\
\text { cial a la } \\
\text { minería } \\
\text { (IEM) }\end{array}$ & $\begin{array}{l}\text { Ley N. }{ }^{\circ} 29789, \\
\text { publicada el } 28 \\
\text { de septiembre de } \\
2011 .\end{array}$ & $\begin{array}{l}\text { Sujetos de la activi- } \\
\text { dad minera que no } \\
\text { contaban con CET y } \\
\text { estaban pagando la } \\
\text { antigua RM. Objeti- } \\
\text { vo: gravar la mayor } \\
\text { rentabilidad obteni- } \\
\text { da por este segmen- } \\
\text { to de empresa. }\end{array}$ & $\begin{array}{l}\text { Utilidad ope- } \\
\text { rativa trimes- } \\
\text { tral }\end{array}$ & $\begin{array}{l}\text { Tasas marginales pro- } \\
\text { gresivas en un rango } \\
\text { de } 2,00 \% \text { a } 8,40 \% \text {, en } \\
\text { función de } 17 \text { tramos } \\
\text { crecientes del margen } \\
\text { operativo de la empre- } \\
\text { sas. }\end{array}$ \\
\hline $\begin{array}{l}\text { Grava - } \\
\text { men es- } \\
\text { pecial a } \\
\text { la mine- } \\
\text { ría (GEM) }\end{array}$ & $\begin{array}{l}\text { Ley N. } .^{\circ} 29790, \\
\text { publicada el } 28 \\
\text { de septiembre de } \\
2011 .\end{array}$ & $\begin{array}{l}\text { Sujetos de la acti- } \\
\text { vidad minera que } \\
\text { al contar con CET } \\
\text { vigentes, no pagaban } \\
\text { la antigua RM. }\end{array}$ & $\begin{array}{l}\text { Utilidad ope- } \\
\text { rativa trimes- } \\
\text { tral. }\end{array}$ & $\begin{array}{l}\text { Tasas marginales pro- } \\
\text { gresivas en un rango } \\
\text { de } 4,00 \% \text { a } 13,12 \% \text {, en } \\
\text { función de } 17 \text { tramos } \\
\text { crecientes del margen } \\
\text { operativo similares a los } \\
\text { del IEM. }\end{array}$ \\
\hline
\end{tabular}

Fuente: elaboración del autor.

Para hacer frente al no pago de la antigua RM por parte de las empresas más grandes de la minería peruana, se creó el gravamen especial a la minería (GEM), el cual se paga también sobre la utilidad operativa. Tanto la nueva RM como el GEM son instrumentos fiscales no tributarios. En la misma fecha en que estos se crearon, nació un nuevo instrumento tributario: el impuesto especial a la minería (IEM), el cual -al menos en el plano declarativo- buscó gravar la mayor rentabilidad del segmento de empresas que comenzaría a pagar la Nueva RM. Se aplica también sobre la utilidad operativa.

\section{PRECISIÓN DE LOS INSTRUMENTOS FISCALES Y RECAUDACIÓN ÓPTIMA DE LA RENTA MINERA}

La precisión de un instrumento fiscal, entendido este concepto como el grado de eficacia (mayor recaudación) y neutralidad del mismo (no altera las decisiones de 
inversión de los agentes económicos), involucra también su capacidad para controlar los grados de libertad con que cuenta el contribuyente para eludir o evadir dicho instrumento. Desde esta perspectiva, la política fiscal minera implementada en el Perú durante el presente siglo, en particular durante la década de bonanza minera, no se ha caracterizado por una alta precisión. No permitió un incremento de los ingresos fiscales en la misma medida en que aumentaban las utilidades extraordinarias del sector. Durante el período 2005-2012, mientras que la utilidad neta (después de impuestos) de las empresas mineras aumentaba a una tasa de crecimiento media anual de 31,4 \%, el impuesto sobre sociedades lo hacía a una tasa de 20,6\%, en tanto que el conjunto de los ingresos vinculados a la renta minera (tributarios y no tributarios) $^{12}$ aumentaba a una tasa de 23,3 \% (ver gráfica 3). Se trató, en suma, de un régimen fiscal más bien regresivo, en el sentido que no permitió una participación creciente del Estado en la renta minera.

Gráfica 3. Sector minero: utilidades e ingresos fiscales 2005-2012 (tasa de crecimiento promedio, en porcentajes)

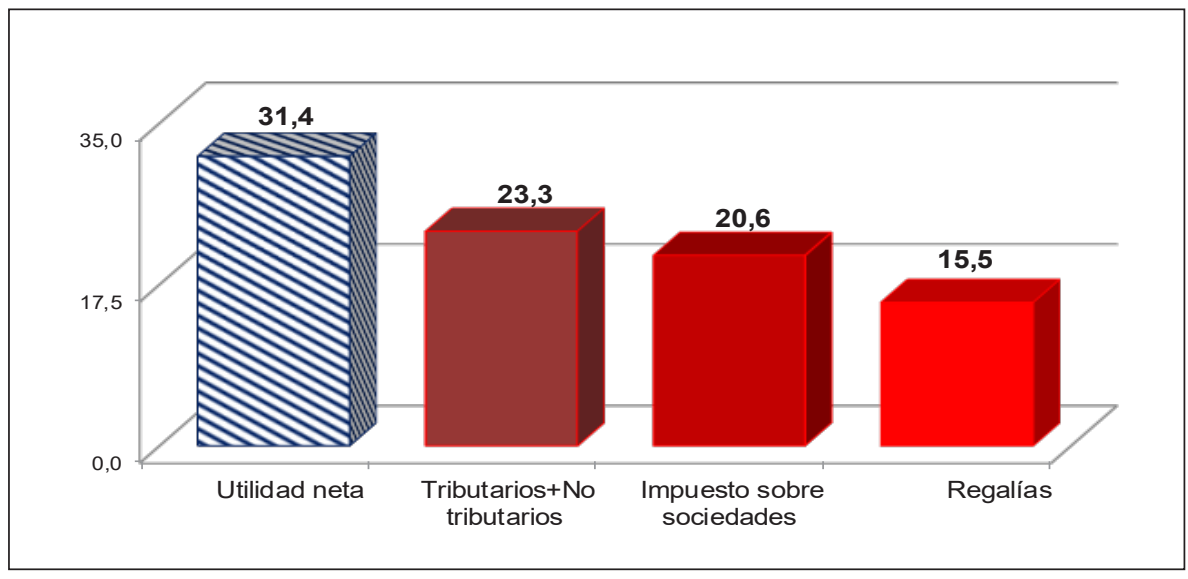

Fuente: Superintendencia Nacional de Aduanas y de Administración Tributaria (Sunat).

Varios aspectos de la política fiscal minera aplicada en el país contribuyen a explicar este resultado.

\subsection{La elusión fiscal}

La debilidad institucional del país permitió -en la práctica- la elusión de la antigua RM. Las empresas mineras más grandes del país recurrieron al Tribunal de Garantías Constitucionales y denunciaron el cobro de la antigua RM como inconstitucional,

12 Impuesto sobre sociedades, IEM, regalías (antigua y nueva) y GEM. 
discriminatorio y confiscatorio. Si bien estos argumentos fueron rechazados por dicho Tribunal en abril de 200513, concluyendo que la Ley de Regalías Mineras era de cumplimiento obligatorio, las mineras se valieron de argumentos elusivos y aprovecharon la reacción dubitativa del Estado para no pagar regalías ${ }^{14}$. Ello impidió una adecuada apropiación de la renta minera por parte del Estado, precisamente en los años de mayor alza del precio de los metales. Mendoza y De Echave (2016) estiman que, entre junio de 2004 y septiembre de 2011, once mineras -amparadas en sus CET- habrían dejado de pagar US\$1.591 millones por concepto de la antigua RM. Del total de regalías que el Estado debió haber recaudado si todas las mineras hubiesen cumplido con la Ley, solo el 40 \% aproximadamente fue recaudado de manera efectiva. Al tratarse de ingresos fiscales destinados a los GL y GR, fueron estos los directos perjudicados.

\subsection{Las deducciones cruzadas}

Un mecanismo, legalmente establecido, para reducir la carga fiscal de las empresas es el de las deducciones cruzadas. Es decir, el monto pagado en cumplimiento de una obligación fiscal es deducido en el pago de otro tributo, con lo cual los ingresos netos se reducen y se debilita así la eficacia del instrumento fiscal. En el Perú, los montos pagados por concepto de nueva RM, IEM y GEM, son deducibles como gasto en la determinación del impuesto sobre sociedades; en consecuencia, disminuyen su base imponible y el monto a pagar.

Un efecto similar tuvo el denominado PMSP, pues si bien estos fondos no eran deducibles para fines tributarios, las empresas que sí venían pagando la antigua RM deducían de su aporte al PMSP una cantidad igual al 64,4 \% de la cantidad anual pagada por concepto de la antigua RM, con lo cual el aporte neto al PMSP se reducía de manera sustancial ${ }^{15}$. Además, según Mendoza y De Echave (2016), no todas las empresas mineras suscribieron los convenios del PMSP. Durante los casi cinco años que estuvo vigente este programa (2007-2011), el 80,7 \% de los depósitos globales fue efectuado por siete empresas que contaban con CET y por ende no pagaban regalías mineras. Los US\$626 millones que estas depositaron bajo el referido programa, representaron solo el 51,9 \% de los US\$1.205 millones que habrían dejado de pagar por concepto de regalías. Es decir, el PMSP se mostró poco eficaz para compensar los ingresos fiscales no recaudados debido al no pago de regalías mineras.

\footnotetext{
13 Resolución del Tribunal Constitucional del 1 de abril de 2005 (expediente N. ${ }^{\circ}$ 0048-2004-PI/TC).

14 Ver al respecto Cooperacción (2007).

15 Este porcentaje $(64,4 \%)$ representa el monto total pagado por concepto de la antigua RM, neto de su efecto tributario.
} 


\subsection{La reducción de la base imponible}

El cambio introducido en el régimen fiscal minero en septiembre de 2011 no generó la fuerte oposición y rechazo que tuvo la antigua RM en 2004. La reacción condescendiente de las mineras frente al nuevo esquema tributario tiene una explicación relativamente sencilla: los tres nuevos instrumentos fiscales (nueva RM, IEM y GEM) tienen un común denominador: la base imponible es la utilidad operativa, ya no el valor bruto de las ventas de concentrado como lo es en la antigua RM. Al aplicarse sobre las utilidades, los nuevos instrumentos fiscales dejan amplios grados de libertad para que -en países con instituciones débiles y altos niveles de evasión- las empresas sobrevaluen sus costos y gastos con el propósito de reducir su utilidad operativa sin que la administración tributaria pueda ejercer un control efectivo. Es lo que la literatura especializada califica como asimetría de la información. En el caso particular de la nueva RM, su implementación tuvo un efecto negativo en la apropiación de la renta minera por parte del Estado.

Para sustentar esta afirmación, en la presente investigación se seleccionaron 20 de las principales mineras que pagaban la antigua RM, las mismas que comenzaron a pagar la nueva RM desde septiembre de 2011. La participación relativa de este grupo en la recaudación total de la nueva RM fue de 62,0 \%, aproximadamente, durante el período 2012-2016. Luego, se procedió a estimar el pago que este mismo grupo hubiese tenido que efectuar bajo el esquema de la antigua RM en ese mismo período. Finalmente, se obtuvo la diferencia entre los montos recaudados por concepto de antigua RM y nueva RM. Las 20 empresas efectuaron un pago total ascendente a US\$531 millones por concepto de nueva RM durante 2012-2016. Este mismo grupo, de haber tributado según el esquema de la antigua RM, hubiese tenido que pagar US\$872 millones (ver gráfica 4). Por tanto, en esta muestra de empresas, el cambio en la forma de calcular el pago de las regalías implicó para el Estado una pérdida de recaudación ascendente a US\$342 millones.

Teniendo en cuenta que las 20 empresas aportaron cerca de las dos terceras partes de la nueva RM, cuya recaudación total ascendió a US\$854 millones durante 2012-2016, una simple extrapolación nos indica que la pérdida de ingresos fiscales en todo el sector habría sido de US\$550 millones, aproximadamente. Es decir, el pago de regalías se habría reducido en 39,2 \%, porcentaje que los GL y R habrían dejado de percibir debido al cambio introducido en el cálculo de las regalías mineras.

La menor recaudación debida a la introducción de la nueva RM fue un resultado previsto por los formuladores de la política fiscal minera, que esperaban compensar con el IEM a ser pagado por el mismo segmento de contribuyentes afecto a la nueva RM. Es decir, el IEM cumpliría dos funciones: por un lado, compensar 
la pérdida de recaudación debido a la implementación de la nueva RM; por otro, recuperar para el gobierno central recursos que bajo el esquema de la antigua RM hubiesen sido destinados a los GL y R. Por tanto, los nuevos instrumentos fiscales implicaron una reasignación en el destino de los recursos recaudados en favor del gobierno central.

Gráfica 4. Nueva RM y antigua RM: estimación de las regalías no recaudadas debido al cambio en la forma de cálculo 2012-2016. Las 20 principales mineras (millones US\$)

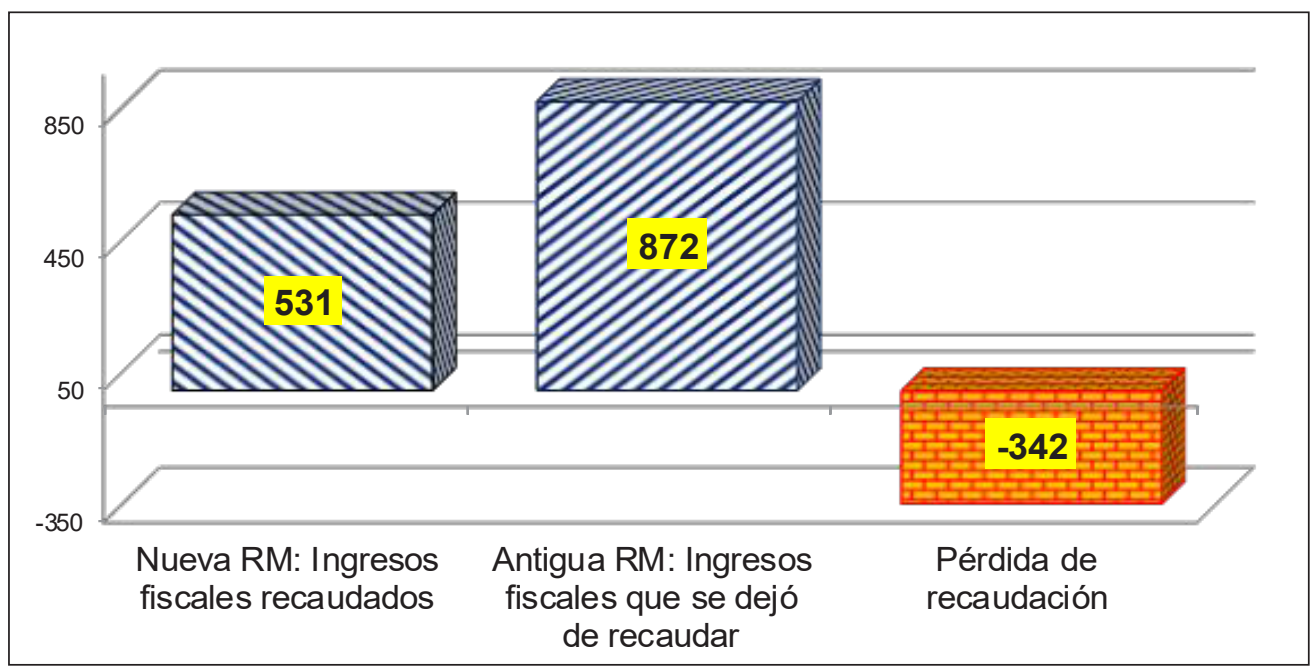

Fuente: Superintendencia Nacional de Aduanas y de Administración Tributaria

Las 20 empresas pagaron US\$362 millones por concepto del IEM durante 20122016; monto que sumado al pago de la nueva RM da un total de US\$892 millones. Esta cifra supera en apenas US\$20 millones el monto de ingresos fiscales que se hubiese podido recaudar bajo el esquema de la antigua RM. Según las estimaciones de este estudio, para el conjunto del sector, dicho saldo positivo habría sido de solo US\$8,8 millones. Si se toma en cuenta que el monto efectivamente pagado por concepto de la nueva RM y el IEM es considerado como gasto para efectos del impuesto sobre sociedades (deducciones cruzadas), el efecto positivo neto de este mayor ingreso fiscal prácticamente desaparece. En cuanto al GEM, tuvo el efecto positivo de obligar a pagar a aquellas mineras que habían venido incumpliendo con el pago de la antigua RM. Sin embargo, en estricto, es un instrumento provisional, pues su eficacia se ha ido extinguiendo conforme fueron venciendo los CET y las empresas involucradas reemplazaron dicho pago por el de la nueva RM y el IEM. Así, luego del fuerte impacto positivo inicial que tuvo su recaudación (US\$357 millones durante 2012), esta se redujo en 91,6 \% entre 2012 y 2016 (ver gráfica 5). 
Gráfica 5. Sector minero: recaudación de los instrumentos no tributarios 2005-2016 (millones US\$)

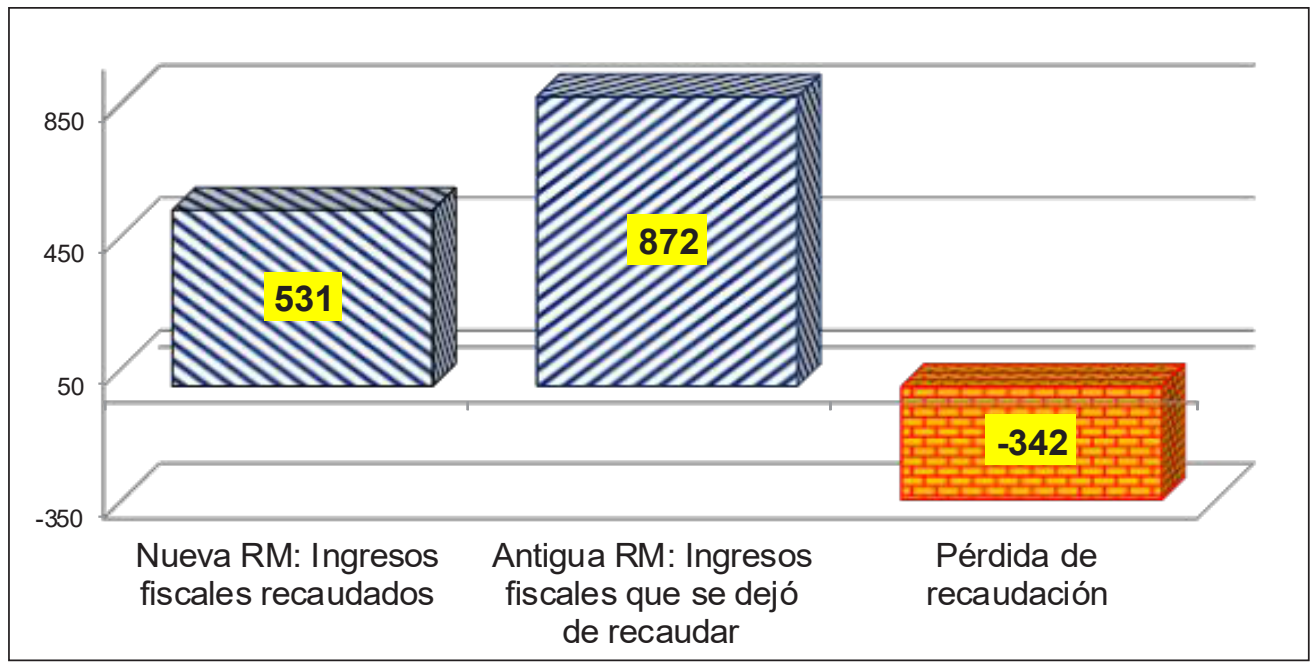

Fuente: Superintendencia Nacional de Aduanas y de Administración Tributaria

\section{INSTRUMENTOS FISCALES ALTERNATIVOS}

Si bien la principal explicación del desplome de los ingresos fiscales vinculados a la renta minera desde 2013 fue la caída del precio internacional de los metales, la poca eficacia de los instrumentos fiscales contribuyó a este resultado. Esta poca eficacia determinó que durante la mayor parte del presente siglo la recaudación de ingresos fiscales provenientes de la renta minera estuviese por debajo de los estándares internacionales. Según cálculos propios, si bien el Estado retuvo en promedio anual el 54,9\% de la renta antes de impuesto ${ }^{16}$ durante 2005-2008; este resultado bajó a 33,5 \% durante 2009-2012, y 18,8 \% durante 2013-2016.

Así, la política fiscal tuvo un rol pasivo y complaciente con respecto al objetivo de capturar de manera óptima la renta minera, desaprovechando en particular el boom minero. Hasta septiembre de 2011, no se exploraron nuevos instrumentos fiscales, aparte de las regalías creadas en 2004, ello a pesar de la variedad de instrumentos alternativos o complementarios que ya eran aplicados en otros países con industrias extractivas. En la presente investigación, se propone la inclusión de dos instrumentos en la política fiscal del sector minero peruano: una regalía minera del tipo ad valorem y un impuesto sobre las rentas de recursos naturales.

$\overline{16}$ Se considera tanto ingresos tributarios como no tributarios. 


\subsection{Regalías ad valorem en reemplazo de las regalías sobre las utilidades}

Las regalías ad valorem se aplican sobre los ingresos brutos. Si bien algunos autores consideran que estas son desventajosas para el productor, cuando la administración tributaria tiene aún limitaciones para un control eficaz de los ingresos, costos y gastos de las empresas, su imposición está justificada en la medida que permite contrarrestar la ya comentada información asimétrica. En tal sentido, proponemos retomar la aplicación de este instrumento fiscal, es decir, la antigua RM, la cual -como se mencionó líneas arriba- fue reemplazada por la nueva RM en septiembre de 2011. Esta propuesta se justifica no solo por los problemas de debilidad institucional e información asimétrica, sino también porque, según vimos en la sección precedente, la antigua RM resulta más eficaz que la nueva RM en términos de recaudación.

Además, al margen de lo que señalan algunos enfoques pesimistas sobre las regalías ad valorem (ver sección 1. Marco teórico), la antigua RM no tuvo un impacto negativo en la inversión ni en las utilidades de las compañías mineras en el Perú. Ambas variables fueron crecientes a lo largo de la década de bonanza, lo cual constituye un buen indicador de que dicho instrumento fiscal no afectó la rentabilidad de las empresas. Como se puede observar en la gráfica 6, durante 2003-2012, la inversión en minería creció a una tasa media anual de 37,0 \%.

Gráfica 6. Perú: inversión en minería 1998-2016 (millones US\$)

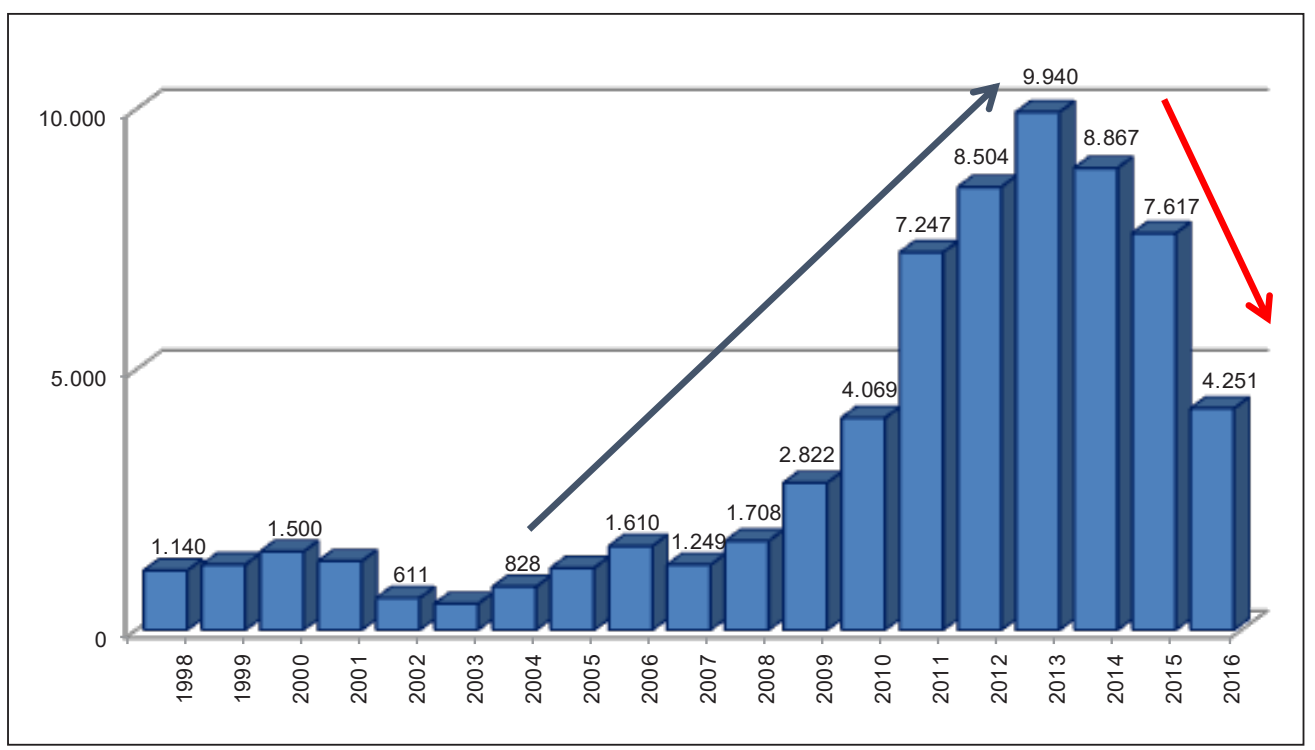

Fuente: MINEM. 
Las utilidades siguieron una tendencia similar durante ese mismo período, con una tasa de crecimiento media anual de 35,2 \% para el caso de las diez mineras más grandes ${ }^{17}$ (ver gráfica 7 ).

Gráfica 7. Sector minero: utilidad antes de impuestos de las diez principales empresas 2003-2016 (millones US\$)

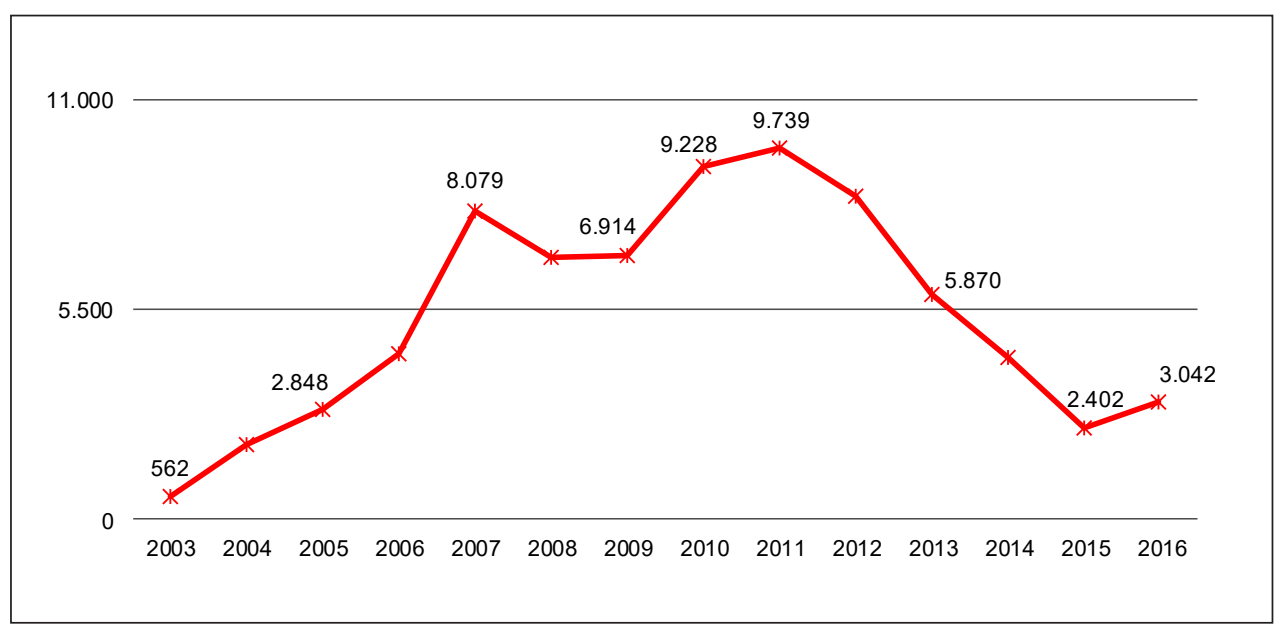

Fuente: Superintendencia Nacional de Aduanas y de Administración Tributaria

De otro lado, a pesar de que la nueva RM -supuestamente más ventajosa que la antigua RM- se venía pagando desde fines de 2011, la inversión minera aletargó su crecimiento desde 2013 y cayó de manera sostenida a partir de 2014: entre 2013 y 2016, cayó en 57,2 \%. Similar tendencia se observa en las utilidades mineras antes de impuesto. En consecuencia, la antigua RM no tuvo efectos negativos en la inversión ni en las utilidades del sector. En estricto sentido, el comportamiento de ambas variables respondió a otro factor principal, distinto a la imposición de las regalías: la evolución del precio internacional de los metales.

La poca eficacia de la regalía ad valorem como instrumento de la política fiscal minera durante el período del boom, se debió a que la debilidad institucional del país permitió -en la práctica-su elusión por parte de las grandes compañías que se ampararon en sus CET. Este problema casi ha desaparecido debido a que la mayor parte de dichos contratos ha finalizado su período de vigencia.

\footnotetext{
17 Durante el período 2003-2012, las diez mineras más grandes aportaron poco más del 76 \% de las utilidades antes de impuesto de la minería metálica.
} 


\subsection{Impuesto sobre las rentas de recursos naturales}

El RRT, o impuesto sobre las rentas de recursos naturales, al cual se hace referencia en el marco teórico, forma parte del grupo de los impuestos que gravan las rentas puras. Land $(2008$, p. 15) considera que su potencial para maximizar la recaudación de ingresos fiscales provenientes de las industrias extractivas "es bastante alto y supera al de otros impuestos progresivos". Por su parte, Daniel, Adedeji y Medas (2007, p. 69) sostienen que el RRT "deja muchas ganancias adicionales en manos de los inversionistas, al mismo tiempo que permite al gobierno participar de manera progresiva en las utilidades, por encima de los niveles requeridos o anticipados".

Sobre la operatividad de este impuesto, Daniel, Adedeji y Medas (2007) explican que el RRT se aplica cuando el flujo de caja de un proyecto minero se vuelve positivo luego de haber alcanzado una tasa mínima de retorno. Funciona como un cálculo de flujo de efectivo descontado. Es decir, los flujos de efectivo negativos (derivados, principalmente, de los gastos iniciales de exploración y desarrollo) serán compensados por los flujos de efectivo positivos. Si al final de un determinado año fiscal el saldo es negativo, este se traslada al año siguiente, pero incrementado en un porcentaje (uplift) que representa la tasa mínima de retorno.

Este proceso continúa periodo tras período hasta cuando el saldo negativo acumulado sea totalmente compensado por flujos de efectivo positivos. El saldo positivo así obtenido es el que se grava al tipo o tasa establecido para el RRT. Una vez pagado este impuesto, el saldo se fija a cero y el RRT sigue siendo aplicado sobre los flujos de efectivo positivos registrados en los períodos subsiguientes. De esta manera, los mismos flujos de efectivo no se gravan dos veces. Desde esta perspectiva, dos serían las únicas diferencias significativas del RRT con respecto al cálculo del impuesto sobre sociedades estándar. Por un lado, los pagos de intereses financieros no son deducibles por separado debido a que se contabilizan como parte del costo del capital, por otro, no se aplica la depreciación contable porque los gastos de capital se deducen en el mismo período en el cual se incurren. La información requerida para la determinación del RRT es la misma que se utiliza en la declaración del impuesto sobre sociedades. Sin embargo, esta operatividad general del RRT presenta matices en su aplicación práctica. En el recuadro adjunto, presentamos un resumen del esquema aplicado en Australia, el cual -como veremos más adelante- en algo difiere del esquema propuesto por el FMI para el Perú. 


\subsection{Aplicación del impuesto a la renta de recursos minerales en Australia ${ }^{18}$}

En Australia, el impuesto a la renta de recursos minerales (MRRT) contemplaba una tasa nominal de $30 \%$, que era reducida en un $25 \%$ (factor de extracción) para tomar en cuenta las habilidades especiales que necesita el productor minero para extraer el recurso y llevarlo al punto de valoración. Por tanto, la tasa efectiva era de 22,5\%. Se distinguía entre beneficio minero (mining profit) y beneficio MRRT (MRRT profit). El primero se obtiene de restar ingresos menos gastos; el segundo, resulta de restar beneficio minero menos determinados créditos o deducciones (mining allowances). La tasa de 22,5\% se aplica sobre el beneficio MRRT.

El cálculo de los ingresos y gastos se efectúa en el denominado punto de valoración (valuation point) del mineral, es decir, el punto en la cadena de producción minera que separa las operaciones aguas arriba (upstream) y aguas abajo (downstream) o de incorporación de valor agregado. En el MRRT, el cálculo de los ingresos y gastos toma en cuenta solo las operaciones upstream:

- Los gastos incluyen las operaciones directamente relacionadas con la exploración, extracción y transporte del mineral (hasta antes de la planta de beneficio) en el área del proyecto minero. Los gastos de capital no se deprecian a lo largo de su vida útil, pues se deducen de manera inmediata. No se consideran como gasto: los pagos de financiamiento, los costos de adquisición de un proyecto minero, los pagos del impuesto sobre sociedades e impuestos sobre bienes y servicios, entre otros.

- En el caso de los ingresos, se calcula el monto que sea razonablemente atribuible al mineral imponible en la forma en que este se encontraba en su punto de valoración, es decir en la fase upstream.

Así, a diferencia del impuesto sobre sociedades, que grava todas las fuentes de ingresos, en el esquema australiano el MRRT grava solo los beneficios upstream. Los mining allowances, compuestos de créditos y deducciones, reducen el mining profit. El más importante es el crédito por regalías (royalty allowance). Se evita así la doble imposición fiscal. Dicho crédito era aumentado (grossedup), utilizando la tasa de $22,5 \%$ del MRRT.

Las deducciones se conceden cuando el contribuyente incurre en pérdidas (mining loss), las cuales son incrementadas por una tasa de interés (uplift rate), representada por la tasa de bonos a largo plazo (LTBR), para ser aplicadas como una deducción contra los flujos de efectivo positivos en años posteriores. La tasa uplift permite

18 Resumen elaborado sobre la base de The Senate (2012a) y The Senate (2012b). 
que las pérdidas del contribuyente preserven su valor toda vez que bajo el esquema australiano las pérdidas no eran reembolsadas de inmediato. Además, se le suma una prima de $7 \%$ para compensar el riesgo de que el contribuyente nunca pueda utilizar sus pérdidas. Por tanto, la tasa de incremento era de 7 \% más la tasa LTBR. Se procedía de igual manera con los créditos no utilizados por regalías. Además, si el beneficio de un minero en todos sus proyectos era inferior a $\$ 75$ millones durante el año fiscal, no pagaba el MRRT (low-profit offset).

El complejo marco legal australiano distinguía tres casos de aplicación del MRRT según la situación en que se encontraba el proyecto minero. El primero, llamado estándar, se refiere al proyecto que no existía antes del 2 de mayo de 2010, cuando se anunció la implementación del MRRT. El segundo, se refiere a proyectos en los que ya se había producido una inversión cuando se anunció el MRRT. El tercero, toma en cuenta la situación de titulares de la actividad minera con proyectos múltiples. Cada caso tiene sus matices en la aplicación de los mining allowances. En el caso estándar, los allowances relevantes son los créditos por regalía y las deducciones por pérdidas.

\section{Ejemplo: cálculo del MRRT en un caso estándar, tomado de The Senate (2012b)}

Midcap Mining Co. recibe $\$ 500$ millones de ingresos de su proyecto minero durante un determinado año fiscal. Gasta \$120 millones durante sus operaciones upstream y paga una regalía minera de $\$ 37,5$ millones. Sus pérdidas arrastradas del año anterior suman $\$ 50$ millones. La tasa de bonos LTBR es del $6 \%$.

Ingresos mineros $\$ 500 m$

Gastos mineros $(\$ 120 m)$

Beneficio minero $[\mathrm{A}$ $\$ 380 \mathrm{~m}$

Crédito por regalías [regalía pagada/0,225 $(\$ 166,7 \mathrm{~m})$

Deducción por pérdidas [pérdida anterior x (LTBR + 7\%)] $(\$ 56,5 \mathrm{~m})$

Total de créditos y deducciones [B

Beneficio MRRT [A - B] $\$ 156,8 m$ Impuesto a pagar [Beneficio MRRT x 0,225] $\$ 35,3 \mathrm{~m}$

Si bien la implementación administrativa del RRT puede resultar algo compleja, ello se ve compensado cuando los ingresos fiscales en juego son elevados. Esta puede ser la razón del por qué el RRT es bastante utilizado en la industria petrolera. 
Sin embargo, señala Land (2008, p.15), ello "no debería excluir la consideración de su uso en la minería en situaciones de alto potencial de renta".

El principal problema con el RRT es la determinación de la tasa de retorno apropiada. No obstante, para Daniel, Adedeji y Medas (2007, p.69), ello se puede solucionar mediante una "licitación donde la competencia esté asegurada, o mediante inteligencia de mercado que investigue sobre el costo del capital y los retornos en la industria minera". También se puede tomar como referencia la tasa de interés del mercado de bonos, como en el esquema australiano.

Como se indicó en la tercera sección de la presente investigación, al comenzar el gobierno del presidente García (julio 2006-julio 2011), una misión de asistencia técnica del FMI visitó el país para asesorar al Ministro de Economía y Finanzas sobre regímenes fiscales para industrias de recursos naturales no renovables. Luego de evaluar el régimen fiscal minero peruano, la misión del FMI recomendó la aplicación del RRT para que el gobierno capturara una participación más alta de la renta minera. Sin embargo, ello no fue tomado en cuenta. En la presente investigación, se suscribe dicha recomendación.

En el informe elaborado por la misión del FMI, que puede ser consultado en Daniel, Adedeji y Medas (2007), se recomienda implementar el RRT a una tasa de $25 \%$ si se impone después del impuesto sobre sociedades ${ }^{19}$, con una tasa uplift de aproximadamente $15 \%$ para incrementar los flujos negativos de efectivo no recuperados. Bajo este esquema, el saldo de los desembolsos netos negativos de efectivo sobre el que se aplica la tasa uplift incluye todos los demás impuestos y los gastos de exploración del proyecto. Es decir, el impuesto sobre sociedades es tratado como una deducción en el cálculo del RRT. Obviamente, se trata de tasas referenciales que tendrían que ser reevaluadas en el momento de su aplicación. Según la misión del FMI, el RRT también se puede calcular antes del impuesto sobre sociedades, en cuyo caso su pago se considera como una deducción (al igual que una regalía) en la determinación del impuesto sobre sociedades.

La misión del FMI opinó que el RRT debía aplicarse en reemplazo de la regalía minera y de los dos puntos adicionales sobre el impuesto sobre sociedades que el gobierno peruano exige para la firma de un CET. Sin embargo, dejó abierta la posibilidad de

9 Según Daniel, Adedeji y Medas (2007), la misión del FMI estimó una tasa marginal del impuesto sobre la renta minera de 49,65 \%: 30 \% por concepto del impuesto sobre sociedades (tasa vigente en 2006), $25 \%$ de RRT sobre el saldo y 4,1 \% sobre el residual por concepto de retención por distribución de dividendos. 
conservar la regalía ad valorem, en cuyo caso su pago debía ser considerado como un crédito en el cálculo del RRT. Este esquema impositivo es coherente con los resultados del modelo de simulación que el FAD del FMI utiliza para el análisis fiscal de las industrias extractivas (FARI, por sus siglas en inglés: Fiscal Analysis of Resource Industries). En efecto, según el FMI (2012, p.26), un régimen que combine una regalía ad valorem con tasa moderada, un impuesto sobre sociedades estándar y un RRT "tiene ventajas considerables" para los países en desarrollo. Ello es así porque: 1) la regalía "garantiza que haya ingresos desde la primera unidad de producción"; 2) el impuesto sobre sociedades garantiza: i) "que el rendimiento normal del capital sea gravado al igual que en otros sectores de la economía", ii) "que las empresas puedan acreditar los impuestos pagados en el extranjero cuando están sujetas a un régimen de renta mundial"; 3) el RRT captura los ingresos potenciales.

En el ya referenciado informe de la misión del FMI se hace la siguiente recomendación adicional ${ }^{20}$ : es importante, tanto en los instrumentos fiscales existentes, como en el RRT propuesto, mantener la eficacia de la administración tributaria para controlar los costos y los ingresos declarados por las empresas mineras. Ello se relaciona con el riesgo siempre latente de la información asimétrica en el sector minero, que otorga grados de libertad para que dichos costos y gastos sean manipulados con el objetivo de reducir la base imponible. Como se puede observar en la gráfica 8 , durante los últimos seis años de nuestro período de análisis, es decir, desde 2011, cuando comienza la aplicación de los nuevos instrumentos fiscales en el Perú (cuya base imponible es la utilidad operativa), los costos y gastos del sector minero han crecido a una tasa media anual de 6,9\%, a pesar de que las ventas cayeron en $3,8 \%$.

Este incremento de costos y gastos ocasiona dos efectos. Por un lado, tiene una influencia directa en la reducción de las utilidades, las cuales se contrajeron en 18,4 \% durante dicho período, por ende, reduce la recaudación del impuesto sobre sociedades. Por otro, los mayores costos y gastos se traducen en elevados saldos a favor del exportador que deben ser devueltos a los mineros, reduciendo así los ingresos fiscales netos del país. En el referido período, las devoluciones al sector se incrementaron a una tasa promedio anual de $35,7 \%$.

20 La misión del FMI recomendó también simplificar los CET, implementados en el Perú desde 1991, para que, entre otros aspectos, no afectaran la operatividad de la administración tributaria. Como bien señalan Guj et al. (2013, p.xii): "por su propia naturaleza, tales acuerdos limitan severamente la capacidad del gobierno para introducir cambios futuros por cualquier medio que no sea la negociación". 
Gráfica 8. Sector minero: ventas netas, costos más gastos, utilidades y devoluciones 2005-2016 (millones US\$)

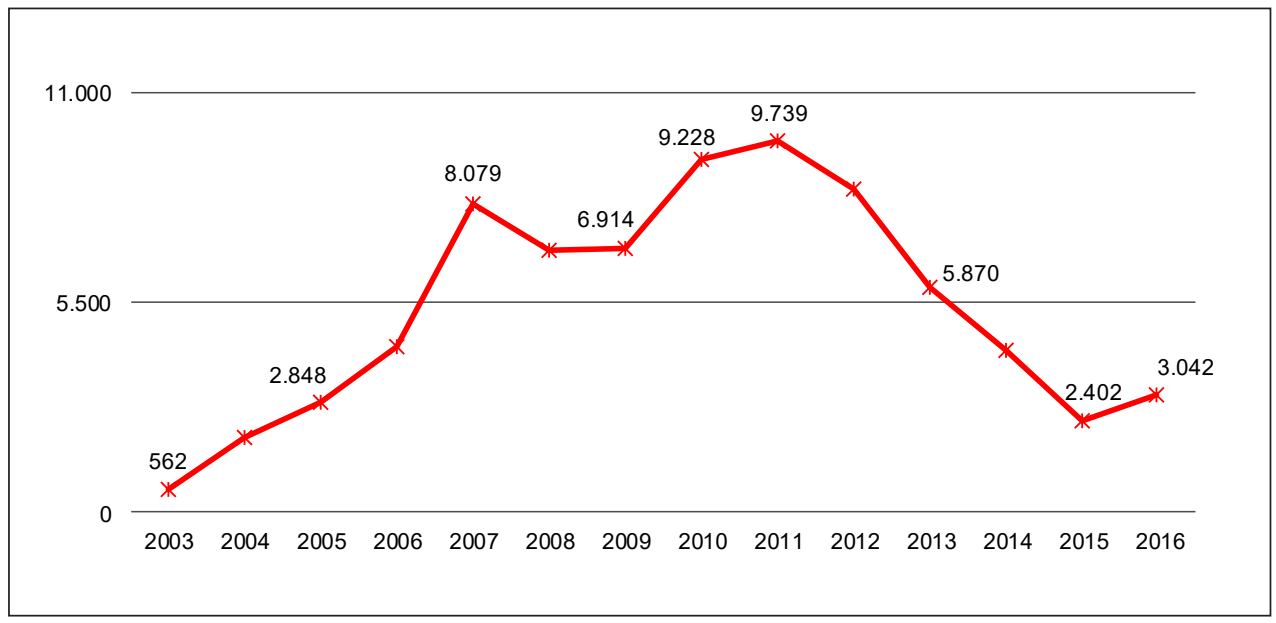

Fuente: Superintendencia Nacional de Aduanas y de Administración Tributaria

Estos resultados, además de los ciclos al alza del precio internacional de los metales, justifican una reformulación de la política fiscal minera en el Perú en la dirección que hemos tratado de fundamentar en la presente investigación.

\section{CONCLUSIONES Y RECOMENDACIONES}

Dos convicciones deben ser resaltadas. Por un lado, cuando la renta económica que se obtiene de la explotación de los recursos naturales no renovables alcanza valores extraordinarios - debido al incremento de precios o la reducción sustantiva de los costos de producción-, el Estado tiene la obligación -en tanto propietario de estos recursos- de utilizar los instrumentos fiscales que le aseguren una apropiación óptima de la renta generada, bajo un criterio de progresividad fiscal. Por otro, la información asimétrica entre la administración tributaria y las empresas mineras debe ser tomada muy en cuenta en el diseño de instrumentos de política fiscal que busquen gravar de manera óptima la renta económica en las industrias extractivas.

En el Perú, la política fiscal minera ha tenido un rol pasivo y complaciente en el logro de dicho objetivo, lo cual se hizo particularmente evidente durante la década de bonanza del precio de los metales. A pesar de la variedad de instrumentos alternativos o complementarios que ya eran aplicados en otros países con industrias extractivas, no se exploraron nuevos instrumentos fiscales hasta septiembre de 2011.

No obstante, estos nuevos instrumentos fiscales, al gravar la utilidad operativa, también han resultado poco eficaces, pues dejan abierta la posibilidad de manipular 
costos y gastos para obtener un trato fiscal más favorable. En este contexto, proponemos retomar las regalías ad valorem para contrarrestar la información asimétrica, que se traduce en la posibilidad de sobreestimar costos y subdeclarar ganancias o flujos de efectivo por parte de las compañías mineras. Sin embargo, este solo instrumento no tributario, además del impuesto sobre sociedades, resultan insuficientes para capturar de manera óptima la renta minera en períodos de ganancias extraordinarias, debiendo optarse también por un impuesto como el RRT, que permite capturar los mayores ingresos potenciales.

\section{BIBLIOGRAFÍA}

Boadway, Robin y Keen, Michael (2014). Rent taxes and royalties in designing fiscal regimes for non-renewable resources. En: Cesifo Working Paper Series, n. ${ }^{\circ}$ 4568, enero, 44 p.

Chen, Duanjie y Perry, Guillermo (2015). Mining taxation in Colombia. En: SPP Research Papers: The School of Public Policy, University of Calgary, vol. 8, n. ${ }^{\circ} 7,42 \mathrm{p}$.

Congreso de la República del Perú. (23 de junio de 2004). Ley de Regalía Minera. [Ley 28258]. Recuperado de: http://biblioteca.unmsm.edu.pe/redlieds/Recursos/archivos/Descentraliza ci\%C3\%B3nRecursosEcon\%C3\%B3micos/Peru/28258.pdf

Cooperacción (2009). La crisis internacional y sus efectos en la tributación y la contribución social del sector minero. Documento de Trabajo. Lima, Perú: Cooperacción, 36 p.

Cooperacción (2007). Tributación y distribución de las sobreganancias mineras en el Perú. Documento de Trabajo. Lima, Perú: Cooperacción, 54 p.

Cuevas, Claudia; Cabaña, Paloma y Rojas, María (2009). El royalty y su impacto en la inversión minera en Chile. Santiago, Chile: Universidad de Chile, 164 p.

Daniel, Philip; Adedeji, Olumuyiwa y Medas, Paulo (2007). Peru. Fiscal regimes for extractive industries. Washington D.C., Estados Unidos de América: International Monetary Fundation, 71 p.

FMI -Fondo Monetario Internacional- (2012). Fiscal regimes for extractive industries: Design and implementation. Washington, D.C., Estados Unidos de América: FMI, 81 p.

Garnaut, Ross (2010). The new australian resource rent tax. Melbourne, Australia: The University of Melbourne, $20 \mathrm{p}$.

Gómez Sabaíni, Juan Carlos; Jiménez, Juan Pablo y Morán, Dalmiro (2015). El impacto fiscal de la explotación de los recursos naturales no renovables en los países $\overline{\text { de América Latina y }}$ el Caribe. Santiago de Chile, Chile: NNUU-CEPAL, 87 p.

Guj, Pietro; Bocoum, Boubacar; Limerick, James; Meaton, Murray y Maybee, Bryan (2013). How to improve mining tax administration and collection frameworks: A sourcebook. Perth, Australia: Center for Exploration Targeting, 139 p.

Guj, Pietro (2012). Mineral royalties and other mining-specific taxes. Crowley, Australia: International Mining for Development Centre, $15 \mathrm{p}$.

ICMM -International Council on Mining and Metals- (2009). Minerals taxation regimes. A review 
of issues and challenges in their design and application. Australia: ICMM, 80 p.

Land, Bryan (2008). Resource rent taxation - theory and experience. Washington D.C., Estados Unidos de América: International Monetary Fundation, 16 p.

Lora, Eduardo; Corbacho, Ana y Fretes, Vicente (2013). Recaudar no basta. Los impuestos como instrumento de desarrollo. Washington D. C., Estados Unidos de América: BID, 420 p.

Mendoza, Armando y De Echave, José (2016). ¿Pagaron lo justo? Política fiscal peruana en tiempos del boom minero. Lima, Perú: OXFAM y Cooperacción, 139 p.

The Senate (2012a). Minerals Resource Rent Tax Bill 2011. [Provisions] and related bills. Camberra, Australia: Economics Legislation Committee-The Parliament of The Commonwealth of Australia. Parliament House, 165 p.

The Senate (2012b). Revised explanatory memorandum. Camberra, Australia: The Parliament of the Commonwealth of Australia. Parliament House, 422 p.

Torres Cuzcano, Víctor (2018). Boom minero, política fiscal y corrupción. Documento de Trabajo Omega Beta Gamma 01, Grupo de investigación Omega Beta Gamma. Lima, Perú: Universidad Nacional Mayor de San Marcos, 6 p.

Torres Cuzcano, Víctor (2015). Minería ilegal e informal en el Perú: impacto socioeconómico. Lima, Perú: Cooperacción, 57 p.

Torres Cuzcano, Víctor (2014). Grupos económicos y bonanza minera en el Perú. En: Apuntes, vol. XLI, n. ${ }^{\circ}$ 75, julio-diciembre, p. 171-210.

Torres Cuzcano, Víctor (2013). Grupos económicos y bonanza minera en el Perú. El caso de cinco grupos mineros nacionales. Lima, Perú: Cooperacción, 299 p. 